\title{
O mercado editorial e a nova direita brasileira
}

\section{Leonardo Nóbrega da Silva ${ }^{1}$}

\section{Resumo}

O presente artigo tem como objetivo analisar a emergência da publicação de autores relacionados à nova direita no Brasil tendo como foco principal a trajetória da editora Record. A editora, fundada em 1940, passou por um processo de expansão nos anos 1990 com a aquisição de editoras historicamente ligadas ao campo intelectual da esquerda como a Civilização Brasileira e a Paz e Terra. Nos anos 2000, a Record deu uma nova guinada que ficou marcada sobretudo pela contratação do editor Carlos Andreazza, que passou a coordenar o catálogo de não ficção da editora, vindo a ser reconhecido como um dos maiores propulsores da nova leva de intelectuais de direita. Argumenta-se que o surgimento da nova direita como um gênero editorial consolida um processo que já vinha se desdobrando nas redes sociais e em âmbitos culturais mais restritos, passando a dar nova e mais ampla configuração a este universo.

Palavras-chave: Nova direita; Mercado editorial; Sociologia histórica da edição; Brasil - Século XXI.

\section{Publishing Industry and the New Brazilian Right}

\section{Abstract}

The aim of this article is to analyze the emergence of the publication of authors related to the new right in Brazil, having as main focus the path of Record. The publisher, founded in 1940, underwent a process of expansion in the 1990s with the acquisition of publishers historically linked to the intellectual field of the left as the Civilização Brasileira and Paz e Terra. In the 2000s, Record took a new turn which was marked mainly by the hiring of the publisher Carlos Andreazza, who began to coordinate the publisher's non-fiction catalog, and was recognized as one of the main promoters of the new wave of right wing intellectuals. It is argued that the emergence of the new right as an editorial genre consolidates a process that was already unfolding in social networks and in more restricted cultural contexts, giving a new and broader configuration to this universe.

Keywords: New Right. Publishing Industry. Historical sociology of the edition. Brazil - 21st Century.

1 Doutorando no Departamento de Sociologia do Instituto de Estudos Sociais e Políticos (IESP) da Universidade do Estado do Rio de Janeiro (UERJ) e professor substituto do Departamento de Ciências Sociais da Universidade Federal de Juiz de Fora (UFJF). 


\section{Introdução}

As discussões políticas no Brasil têm se dado de forma bastante polarizada, opondo esquerda e direita em campos que se pretendem diametralmente opostos e que por muitas vezes flertam com a total incapacidade de diálogo. A face mais visível dessa disputa é a que se desdobra nas redes sociais, em blogs e sites de opinião, colunas de jornal e nas interações presenciais entre amigos, colegas e familiares. Outra face fundamental de materialização dessas tensões, menos visível e, também por isso, menos analisada - embora de fundamental importância - é a do mercado editorial.

A disputa de ideias no campo político encontra nos livros uma forma mais perene (DARNTON, 1993) e pretensamente mais prestigiosa de inscrição, que se imbrica nos embates públicos e têm em si a capacidade de alcançar ampla audiência, seja pela leitura direta dos livros, seja pela disseminação de suas ideias por comentaristas e compartilhamento nas redes sociais. A interação entre as esferas de produção cultural, a política e o mercado possibilitam compreender processos decisivos que condicionam a complexa rede de produção e circulação de conhecimentos.

O espaço recentemente ocupado pelos autores vinculados ao campo político da nova direta no mercado editorial brasileiro chama a atenção para a possível emergência de um novo gênero editorial ${ }^{2}$. Tratar uma diversidade de livros como constituintes de um gênero editorial específico significa observar um conjunto de práticas culturais e saberes especializados que dão certa homogeneidade aos autores publicados e estabelecem um diálogo intelectual e mercadológico com os leitores. A editora Record se destaca neste processo tanto pela guinada que deu na construção do seu catálogo, ao conciliar os autores de esquerda com uma nova leva de autores vinculados à direita, quanto pela capacidade que tem de difusão de seus livros, dando uma nova configuração aos debates que vinham se articulando em uma esfera cultural até então bastante restrita.

\section{A edição como objeto de análise e as modificações no mercado editorial}

A atividade de edição faz parte de um sistema amplo de produção e circulação de conhecimento, que conta também com livrarias, gráficas, universidades, bibliotecas, meios de comunicação de massa (jornal, rádio, televisão, cinema), além dos intelectuais e dos leitores, como enfatiza o historiador Robert Darnton (2010). Analisar a dinâmica de publicação de livros vinculados à nova direita no Brasil significa, portanto, compreender o campo editorial, a interação entre seus atores, a construção de redes, relações institucionais e a capacidade dos livros, seus autores e leitores, envolverem-se em um debate público mais amplo. Neste universo, a atividade editorial ocupa espaço fundamental de atividade intermediária entre o texto escrito e o leitor (MEDEIROS, 2010), propondo obras, configurando catálogos e estabelecendo com o público um vínculo mais ou menos efetivo, a depender de suas capacidades e acertos.

Como afirma Bourdieu (BOURDIEU, 1999), ao analisar a dinâmica do mercado editorial literário francês, o editor é alguém que tem o poder extraordinário de tonar algo público, levar um texto e um autor a existência numa esfera ampla de discussão. Esse tipo particular de criação envolve a consagração, entendida como a transferência de capital simbólico (como na escrita de um prefácio, por exemplo). A transferência é ainda maior quando os editores são, eles mesmos, consagrados. A posição de uma editora no campo editorial depende, portanto, do acesso a recursos escassos (econômico, simbólico,

2 A noção aqui utilizada é derivada da utilização feita por Gustavo Sorá (2004) ao tratar das ciências sociais como gênero editorial. Para um desdobramento da utilização deste conceito no Brasil tendo como foco a emergência das ciências sociais como gênero editorial, cf.: (SILVA, 2018b). 
técnico) e o poder que esses recursos conferem.

A atividade editorial pressupõe um saber especializado e práticas culturais relacionadas ao seu funcionamento interno. Dentre esses saberes especializados está o trato com o ciclo editorial pelo qual um livro passa no decorrer de sua vida, que envolve a escolha do texto a ser editado, a tiragem e o preço de capa, a decisão por realizar reimpressão ou a retirada de circulação, etc. As decisões editoriais relativas ao ciclo editorial de um livro estão intimamente relacionadas à cadeia editorial como um todo, o que envolve a rede de organizações e atividades relacionadas à publicação, distribuição e venda do livro (THOMPSON, 2005). A disposição destas diversas formas de conhecimento e a relação entre elas é fundamental para o posicionamento de uma editora no campo editorial.

É necessário, portanto - ao se analisar o crescimento de um campo de discussões específico, como a da nova direita no Brasil -, atentar não só para ideias, textos, autores e contexto social, mas também para as editoras que viabilizam tais publicações. A posição que estas editoras ocupam no campo, suas trajetórias e os recursos que possuem indicam a sua capacidade de estabelecer estratégias que sejam mais ou menos exitosas.

Fundada em 1942 por Alfredo Machado e Décio Abreu, primeiro como distribuidora e posteriormente como editora, a Record viu o seu tamanho triplicar na década de 1990 quando, com a morte de Alfredo, seu filho, Sérgio Machado assumiu a direção da editora, que herdou juntos a seus outros dois irmãos. A inspiração para a ampliação do negócio veio da Random House, editora estadunidense que cresceu comprando outras editoras concorrentes e estabelecendo selos editoriais diversos e muitas vezes dissonantes entre si. Nesse movimento, a Record comprou editoras com catálogos fundamentais da literatura nacional, como a José Olympio e a Bertrand Brasil, e editoras vinculadas historicamente ao pensamento de esquerda, como a Paz e Terra e a Civilização Brasileira.

Esta dinâmica de concentração nos setores de produção e venda de livros não é exclusivamente brasileira, tendo paralelo com diversas outras realidades nacionais. Em análise desenvolvida tendo como objeto os casos britânico e norteamericano, Thompson (2005) observa a existência destas duas tendências fundamentais - a formação de conglomerados editoriais e a formação de grandes cadeias varejistas de livro (incluído aí o comércio online) -, que vêm se consolidando desde meados dos anos 1980 na indústria do livro como um todo. A rivalidade interna a este campo gera tanto homogeneidade quanto diferenciação. Tendo em vista que o campo editorial é diferenciado e cortado por diversos subcampos específicos, as principais editoras em cada um destes nichos tendem a ter catálogos muito parecidos, posto que casos de sucesso tendem a ser seguidos por outras editoras concorrentes. A estrutura competitiva do campo, entretanto, gera, ao mesmo tempo, algum grau de diferenciação e especialização, posto que empresas particulares tendem a consolidar sua posição e reputação em uma determinada área específica, como o campo de publicações literárias, publicações acadêmicas, livros didáticos etc., cada qual com seu tipo de conteúdo específico e destinado a um mercado delimitado, com formas de recompensa e reconhecimento particulares, embora uma mesma empresa possa atuar em diferentes campos concomitantemente. Esta estratégia de atuação múltipla vem sendo adotada pelos grandes grupos editoriais, como é o caso no Brasil da editora Record, com vistas a diminuir os riscos de investimento e fazer novos experimentos mercadológicos, utilizando os selos como formas de estabelecer identificação com o público.

As mudanças pelas quais passa o mercado editorial resulta em uma orientação prioritária para o lucro que tem tomado o lugar dos julgamentos editoriais voltados para a qualidade intelectual e literária das obras (SCHFFRIN, 2006). Uma das manifestações desta nova configuração é a disputa, entre os grandes conglomerados editoriais, pela publicação de best sellers, que se reverte, no universo dos livros 
políticos, na preferência pela publicação de instant books ${ }^{3}$ (SAFERSTEIN, 2017).

O mercado editorial brasileiro nos anos 1990 passava por um momento propício à expansão de uma editora como a Record. Com a implementação do plano Real, em 1994, tem fim um histórico de hiperinflação que apresentava vários entraves para o desenvolvimento do setor, como a incapacidade de investimentos, a imprevisibilidade quanto aos desdobramentos das políticas econômicas e um consumo bastante restrito a setores específicos da classe média. A partir daí consolidam-se tendências que já se pronunciavam desde a década anterior, sendo significativo, nesse momento, o crescimento das redes varejistas, a entrada de capital estrangeiro no mercado nacional e a formação de grandes conglomerados editoriais no país.

As pesquisas sobre produção e vendas do setor editorial brasileiro realizadas anualmente pela Fundação Instituto de Pesquisas Econômicas (FIPE), a pedido do Sindicato Nacional dos Editores de Livros (SNEL) e da Câmara Brasileira do Livro (CBL), medem o número de títulos e exemplares produzidos e vendidos no Brasil e o faturamento total das editoras. A observação da variação no número de títulos em primeira edição ou reimpressão produzidos entre 1990 e 2015 dá uma ideia da expansão do mercado editorial brasileiro, que saltou de pouco mais de 20 mil títulos produzidos em 1990 para $50 \mathrm{mil}$ em 1997 e 60 mil em 2013, embora intercalado com momentos de queda, como observado em 2004, 2009 e em 2015.

Número de títulos em milhares de exemplares em primeira edição e reimpressão entre 1990 e 2015

70

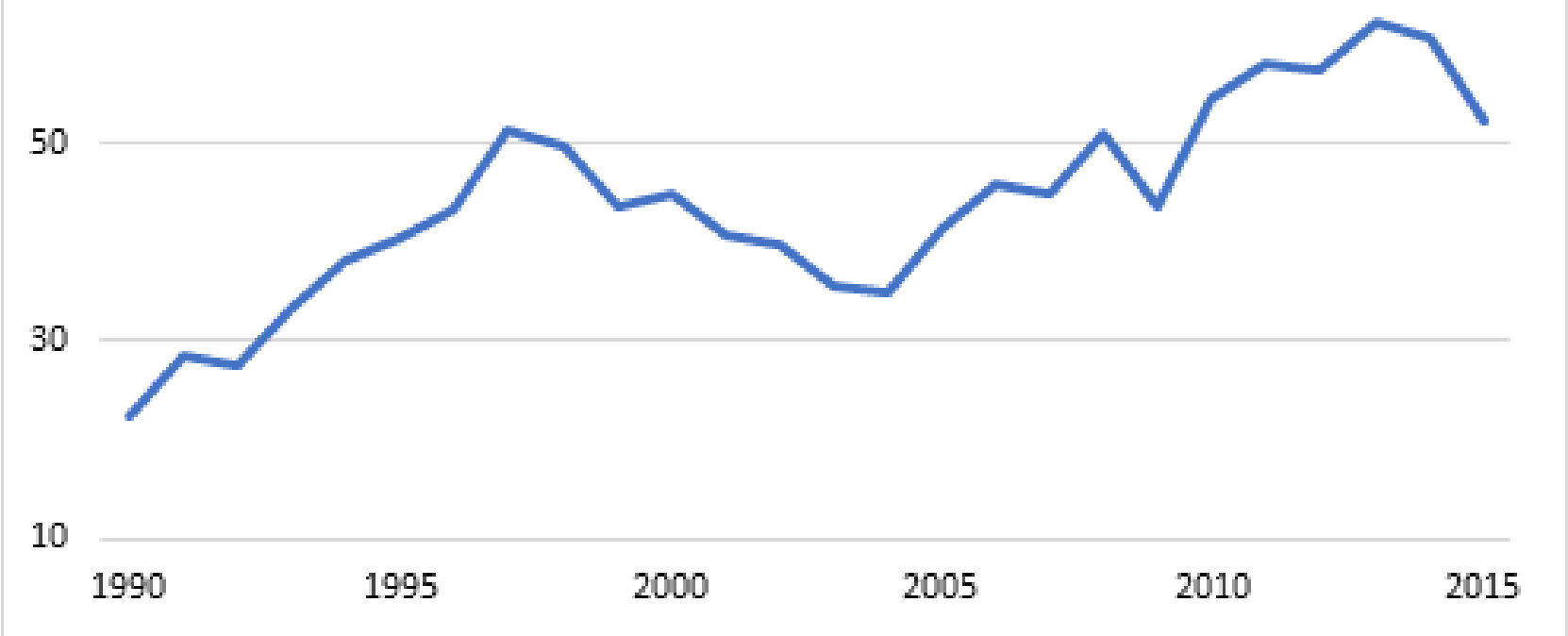

Fonte: Elaboração própria com dados disponibilizados pelo Sindicato Nacional dos Editores de Livros 
Do ponto de vista das vendas, pode-se também falar em expansão. Em 1990 foram vendido cerca de 212 milhões de exemplares. Em 2015, o número de exemplares vendido foi de 390 milhões. Uma explicação possível para esse dinamismo no setor de vendas de livros é a abertura das megalivrarias (HALLEWELL, 2005) nos anos 1990, aliado a uma reorganização da cadeia distributiva do livro, com a ampliação das vendas pela internet, superando, mesmo que timidamente, a dificuldade de distribuição do livro no Brasil, além,éclaro, da expansão do ensino superior e do aumento do poder de compra das classes médias e baixas. Apesar deste crescimento no número de vendas e capacidade distributiva, o setor varejista apresentou uma concentração de capital, acarretando o fechamento de muitas livrarias de menor porte.

Número em milhões de exemplares de livros vendidos entre 1990 e 2015

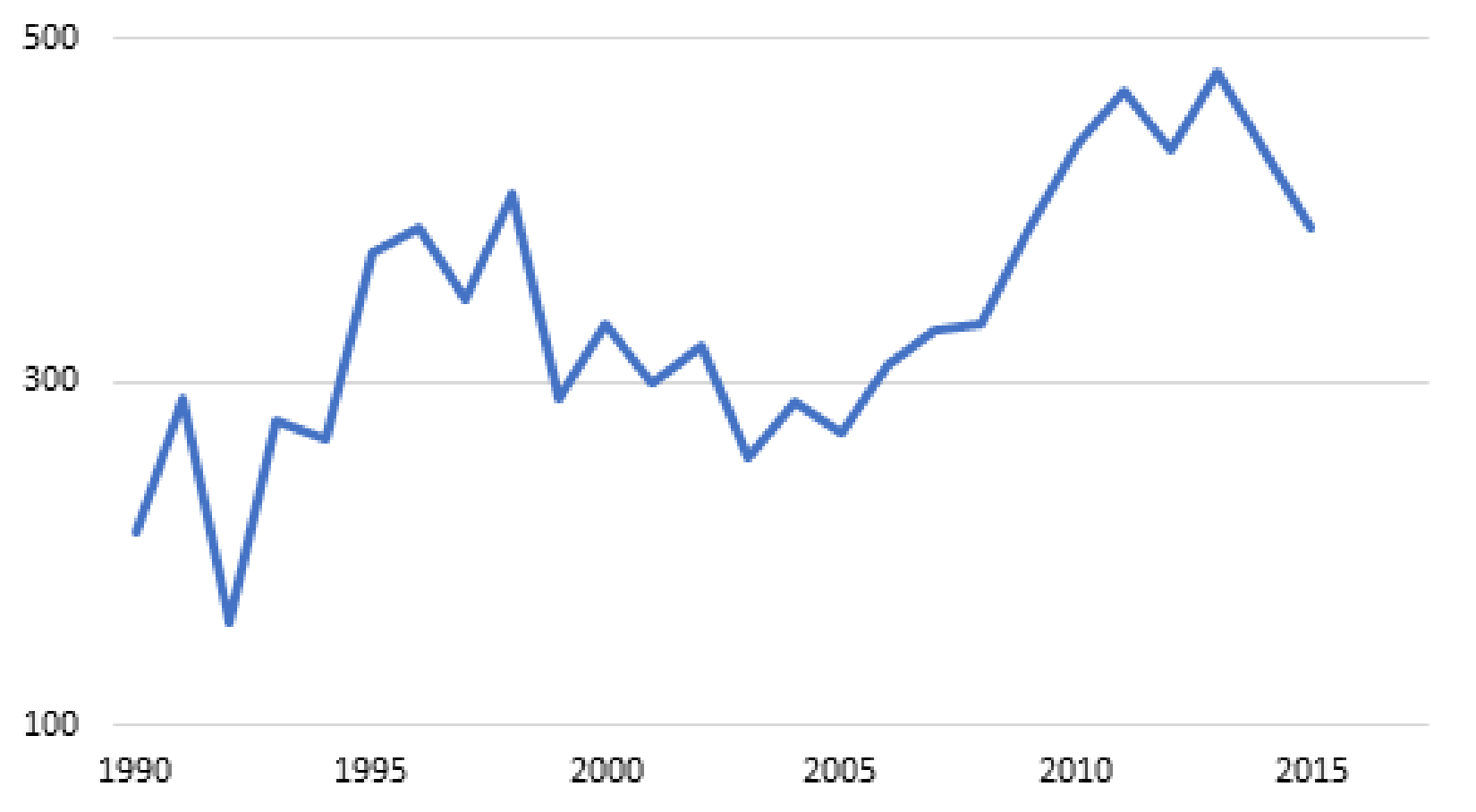

Fonte: Elaboração própria a partir de dados disponibilizados pelo Sindicato Nacional dos Editores de Livros 
Este breve panorama apresenta alguns dos traços mais gerais da movimentação do mercado editorial brasileiro nas últimas décadas, apontando para o crescimento do número de títulos e exemplares e a concentração de selos editorais em grupos com maior capacidade de investimento. A trajetória da Record neste sentido é exemplar das mudanças pelas quais o mercado editorial passou, estabelecendo estratégias de aquisição de editoras que possuíam um catálogo de prestígio e com potencial de vendas, mas que não conseguiram atravessar os momentos de dificuldade.

Além das mudanças econômicas decorrentes da implementação do plano Real, a década de 1990 marcou um momento de inflexão no mercado editorial brasileiro no que diz respeito a seus editores de maior prestígio. Faleceram nesse período José Olympio, dono da famosa editora homônima, Victor Civita, da Abril, Alfredo Machado, da Record, Sério Lacerda, da Nova Fronteira, Caio Graco Prado, da Brasiliense, Jorge Gertum Carneiro, da Ediouro e Ênio Silveira, da Civilização Brasileira (HALLEWELL, 2005). Todos estes nomes foram fundamentais para o mercado editorial brasileiro na segunda metade do século XX. A descentralização de projetos editoriais fortes no campo político de esquerda, como foi o caso da Brasiliense e da Civilização Brasileira, deixou espaço para a ascensão de uma editora como a Boitempo (SILVA, 2018a), que passou a assumir um lugar de destaque neste cenário polarizado das discussões públicas, sem que esta, entretanto, tenha alcançado posição hegemônica na intelectualidade do país como as que a antecederam.

A centralidade alcançada por editoras como a Civilização Brasileira e a Brasiliense se devia, em grande medida, a uma hegemonia da esquerda no campo cultural e acadêmico na segunda metade do século XX, apesar das tentativas de silenciamento empreendidas pelo estado autoritário (SCHWARZ, 1975). Tendo passado por um processo de amadurecimento no período de democratização após o Estado Novo, a intelectualidade brasileira estabeleceu um posicionamento político hegemonicamente de esquerda, que foi se desdobrar durante o período de Ditadura Militar, apesar do processo repressivo que tomou forma a partir de 1968. O distanciamento histórico em relação a este momento e a perda de hegemonia da esquerda na esfera cultural explica, em grande medida, a posição relativamente periférica, embora firme, de uma editora como a Boitempo, e a possibilidade de mudança na política editorial da Record, que passou a explorar o espaço diametralmente oposto no espectro político do campo editorial.

\section{A editora Record e a publicação de autores da nova direita}

O processo de aproximação da editora Record com os autores da nova direita no Brasil é bastante representativo das modificações políticas, sociais e culturais pelas quais o país passou nos últimos anos. Segundo Luciana Villas-Boas - que foi diretora-editorial da Record entre 1995 e 2015 -, Sergio Machado adquiriu a Civilização Brasileira porque os livros da editora "vendiam espetacularmente" . O próprio Sérgio, avalia Luciana, achou irônico - embora não tenha se oposto -, como "liberal convicto" que era, ver a editora "transformada em uma plataforma da esquerda marxista na época do Fórum Social, entre 2001 e 2003", com a publicação de livros como Sem Logo de Naomi Klein e Império de Antonio Negri e Michael Hardt. A preferência por livros de esquerda, embora contrário às convicções pessoais do dono da editora, vendiam bem e, por isso, justificavam uma política editorial voltada para o setor.

Por muito tempo associado ao sistema repressivo da ditadura militar no Brasil, o pensamento de direita se manteve - ao menos

4 VILLAS-BOAS, Luciana. Sergio Machado e Eu. 22/07/2016. Último acesso em http://vbmlitag.com.br/index. php/2016/07/22/sergio-machado-e-eu/ no dia 13/03/2017. 
de forma explícita e em termos de repercussão - ausente das discussões públicas até muito recentemente, quando passou a ganhar maior visibilidade. A ascensão da chamada nova direita no Brasil se deve, além dos fatores já elencados anteriormente - como a distância histórica em relação à ditadura militar e a reestruturação no mercado cultural, associado à emergência da internet -, a outros fatores sociais, tais como: a crise política internacional do Estado de Bemestar Social e do pensamento teórico marxista, tendo como marco a queda do Muro de Berlim; o desenvolvimento de institutos privados, também conhecidos como think tanks ${ }^{5}$, que agregam o pensamento liberal e se organizam fora das universidades; os sucessos e fracassos relacionados à esquerda hegemônica no Brasil, representada pelo Partido dos Trabalhadores; além de uma crise mais ampla no sistema partidário como um todo (CHALOUB; BOM JARDIM, 2016).

O processo de emergência da nova direita no Brasil guarda diversas semelhanças com o que vem ocorrendo nos demais países latinoamericanos, podendo-se caracterizar como parte de um processo histórico de média duração cujos primeiros desdobramentos podem ser localizados no início dos anos 1980, mais especificamente com a crise da dívida de 1982 e a radicalização da agenda neoliberal (GIORDANO, 2014). A criação em 1982 da rede de think tanks Atlas Network deu ensejo a criação de diversas organizações por toda a América Latina. No Brasil a criação do Instituto Liberal, em 1983 na cidade do Rio de Janeiro, por iniciativa do empresário canadense radicado no país Donald Stewart, teve papel pioneiro. Um ano depois foi criado em Porto Alegre o Instituto de Estudos Empresariais (IEE), fundado pelos irmãos William e Winston Ling. As iniciativas, entretanto, esbarraram em dois obstáculos fundamentais: a dificuldade dos próprios empresários de pôr em prática os princípios liberais quando estes eram prejudiciais a seus negócios e a ausência de um número considerável de intelectuais liberais que pudessem influenciar a opinião pública. A adoção de pautas liberais pelos governos Collor e FHC diminuiu o engajamento dos empresários nos think tanks, já que tiveram algumas de suas pautas atendidas. Alguns legados desta primeira fase, entretanto, foram fundamentais para o que se viria a desenvolver depois, principalmente no que diz respeito à institucionalização do movimento - que antes contava apenas com atuações individualizadas -, e a disponibilização de livros e demais materiais informativos, além de investimentos na formação de quadros universitários, principalmente na área de economia (ROCHA, 2015).

Os anos 2000 flagraram a ascensão de governos progressistas de esquerda na América Latina. A eleição de Hugo Chaves na Venezuela em 1998, de Luiz Inácio Lula da Silva no Brasil em 2002 e de Nestor Kirschner na Argentina em 2003 formam alguns dos casos mais representativos, que se espalharam também por outros países da região. Esse processo, entretanto, começou a encontrar resistência e viria a passar por um refluxo na virada da década. No Brasil, o chamado "escândalo do mensalão" marcou o ponto de inflexão, em que parte da classe média passou a ter uma visão crítica em relação ao Partido dos Trabalhadores (SINGER, 2012).

O surgimento do Orkut em 2004 e o sucesso que esta rede social obteve no Brasil permitiu a reunião de pessoas descontentes com os rumos políticos do país e próximas ou interessadas no pensamento liberal. Grupos liberais passaram a se reunir a partir de 2005 no Orkut compostos na sua maioria por jovens estudantes de classe média. À diferença dos think tanks criados nos anos 1980, esses novos grupos contavam

5 Segundo Camila Rocha (2015, p. 262), “Os think tanks podem ser definidos de modo mais genérico como instituições permanentes de pesquisa e análise de políticas públicas que atuam a partir da sociedade civil, procurando informar e influenciar tanto instâncias governamentais como a opinião pública no que tange à adoção de determinadas políticas públicas”. O crescimento, nos Estados Unidos nos anos 1970, de think tanks de caráter mais ativista e de direita serviu como modelo para a criação dos think tanks na América Latina. 
com uma organização mais horizontal e descentralizada, sem tantos recursos, e propondo pautas de mobilização e confrontação, o que os faz se aproximarem dos movimentos sociais tradicionalmente vinculados a esquerda (ROCHA, 2017). As manifestações de junho de 2013 serviram como momento fundamental de atuação desses novos grupos de direita na cena política brasileira. Tem-se como símbolos deste momento a criação do Movimento Brasil Livre (MBL) e a troca no comando do Instituto Liberal, cuja presidência passou a ser ocupada por Rodrigo Constantino. No texto que escreveu em seu blog sobre o cargo que passara a assumir, deixou claro o objetivo de realizar uma disputa política por meio da disseminação do pensamento liberal:

(...) A principal batalha deve ser travada no campo das ideias. O mundo será um lugar mais livre apenas se os liberais vencerem o debate, não por meio da força física, mas dos argumentos. O Brasil vive um vácuo de boas ideias justamente porque a esquerda tem vencido essa batalha nas últimas décadas. Isso precisa mudar. (...). Utilizamos diferentes instrumentos para tanto, tais como palestras, artigos, revistas e livros. (CONSTANTINO apud ROCHA, 2017).

Foi neste contexto de emergência de uma nova geração de think tanks e grupos de discussão sobre o pensamento liberal que a editora Record realizou um movimento amplo de reposicionamento da sua atuação, deixando de lado parte das publicações vinculadas ao pensamento de esquerda e vindo a alcançar o emergente mercado da nova direita. Segundo Luciana Villas-Boas ${ }^{6}$, a decepção com os governos petistas estabelece o início da guinada à direita da editora, com livros como Lula é minha anta (2007) de Diogo Mainardi e O País dos Petralhas (2008) de Reinaldo Azevedo, ambos organizados como coletâneas de artigos publicados em jornais e blogs. Esse movimento se mostrou duradouro e, com a saída de Luciana Villas-Boas da editora, em 2012, Sergio Machado decidiu descentralizar as decisões, contratando editores específicos para cada área de atuação. Nesse movimento, Carlos Andreazza assumiu a área de não ficção da editora, passando a dar o tom das novas publicações alinhadas ao pensamento de direita no catálogo.

\section{A atuação editorial de Carlos Andreazza}

Embora algumas editoras já explorassem o filão da emergente nova direita no Brasil - como a É Realizações, fundada em 2001 -, a guinada dada por uma editora do porte da Record marcou um momento de inflexão neste processo, dando uma visibilidade a publicações de autores que até então alcançavam um público bastante restrito. Um momento simbólico desse processo se deu em 2013 com a publicação de O mínimo que você precisa saber para não ser um idiota, livro organizado por Felipe Moura Brasil, colunista da revista Veja, com artigos de Olavo de Carvalho. A adaptação para o público jovem, na mira do recém-chegado editor Carlos Andreazza, veio a partir da inovação no projeto gráfico $^{7}$ e nas demais escolhas editoriais do livro: "o que fizemos foi dar um tratamento pop ao autor. Nós hypamos o Olavo, desde a escolha do título até a capa" ${ }^{8}$, afirma Andreazza, que a partir de então viria a se consolidar como um dos mais consagrados editores ligados ao pensamento de direita. Com o sucesso comercial do livro de

6 VILLAS-BOAS, Luciana. Sergio Machado e Eu. 22/07/2016. Último acesso em http://vbmlitag.com.br/index. $\mathrm{php} / 2016 / 07 / 22 /$ sergio-machado-e-eu/ no dia 13/03/2017.

7 Para uma discussão sobre a importância do projeto gráficos dos livros, ver Silva (2014).

8 CAMPOS, Mateus. "Editor de nomes conservadores, Carlos Andreazza se firma como voz dissonante do mercado de livros". Jornal O Globo, Rio de Janeiro, 31/03/2016. Último acesso em http://oglobo.globo.com/cultura/ livros/editor-de-nomes-conservadores-carlosandreazza-se-firma-como-voz-dissonante-do-mercado-de-livros17021179\#ixzz4bFGqF5tQ no dia 13/03/2017. 
Olavo de Carvalho, que em menos de dois anos já havia vendido pelos menos 100 mil cópias ${ }^{9}$ número impressionante tendo em vista que as tiragens médias no Brasil não passam de 5 ou 10 mil exemplares -, os próximos livros seguiriam o mesmo percurso. Segundo Carlos Andreazza, "Havia e há uma imensa demanda reprimida, culpa dos cerca de 50 anos em que a produção editorial brasileira excluiu os pensamentos liberal e conservador de suas prensas, por que se recolocassem, com tratamento profissional, as importantíssimas ideias liberais e conservadoras nas prateleiras das livrarias" ${ }^{\prime 0}$.

Carlos Andreazza é neto do ex-ministro dos transportes do governo militar, Mário Andreazza, responsável por obras como a ponte Rio-Niterói e a Transamazônica. Formado em jornalismo pela Pontifícia Universidade Católica do Rio de Janeiro (PUC-RJ), construiu sua carreira em pequenas editoras como a Contracapa, Capivara e a parisiense La Table Ronde, antes de chegar por intermédio de Sônia Jardim, irmã de Sergio Machado -, à editora Record. A ousadia com que estabeleceu uma agenda de publicações de direita agradou a Sergio Machado: "A teoria que a Luciana defendia era que a esquerda lê mais do que a direita. E, para mim, isso sempre fez um certo sentido. $\mathrm{O}$ Andreazza apostou no contrário e, para nossa surpresa, deu certo ${ }^{11}$ ".

A decisão de Carlos Andreazza em trazer um autor como Olavo de Carvalho para o catálogo da Record é bastante representativa do movimento realizado pelo mercado editorial. Olavo de Carvalho foi um dos autores pioneiros da nova direita ao estabelecer polêmicas com intelectuais e acadêmicos de esquerda no pais nos anos 1990 . Entre dezenas de livros escritos, sobre temas os mais variados, desde filosofia a astrologia, Carvalho publicou obras como O jardim das aflições: de Epicuro à ressurreição de César ensaio sobre o materialismo e a religião civil (1995), O imbecil coletivo: atualidades inculturais brasileiras (1996) e O imbecil coletivo II: A longa marcha da vaca para o brejo e, logo atrás dela os filhos da PUC, as quais obras juntas formam para ensinança dos pequenos e escarmento dos grandes (1998). A sua atuação em blogs e sites de internet, que passou a manter com certa regularidade desde 1998, começou a alcançar um público interessado em suas ideias, embora este nicho ainda fosse muito restrito. A organização de um seminário online de filosofia, que teve início em 2007 reunindo milhares de expectadores, serviu como um indicador das mudanças que estavam ocorrendo.

O posicionamento intelectual (BAERT, 2012) assumido por um autor como Olavo de Carvalho, assim como vários dos autores da nova direita no Brasil - sejam discursos, seminários, livros ou qualquer outro produto intelectual -, leva em consideração os aspectos performáticos (estratégias retóricas, formação de redes) e relacionais (o que significa dizer que a intervenção intelectual não tem valor em si, mas depende do status, posição, trajetória do autor e dos outros intelectuais relacionados, bem como do contexto político-social em que está inserido). Atentar para esta questão significa observar não só o posicionamento assumido pelos autores, seus pares e o contexto social mais amplo, mas para as editoras que os publicam e a forma como essas publicações são concebidas. As editoras se estabelecem, desta forma, como atores fundamentais na articulação de estratégias

9 MOURA BRASIL, Felipe. “O Mínimo” bate a marca de 100 mil exemplares vendidos e Olavo de Carvalho é exaltado nas ruas de todo o país. Último acesso em https:/veja.abril.com.br/blog/felipe-moura-brasil/8220-o-minimo-8221-bate-amarca-de-100-mil-exemplares-vendidos-e-olavo-de-carvalho-e-exaltado-nas-ruas-de-todo-o-pais/ no dia 30/08/2018. 10 BORGES, Rodolfo. “A Direita Brasileira que saiu do Armário não para de Vender Livros”. El País. São Paulo, 1 de agosto de 2015. Último acesso em http://brasil.elpais.com/brasil/2015/07/22/politica/1437521284_073825.html no dia 03/03/2017.

11 CAMPOS, Mateus. "Editor de nomes conservadores, Carlos Andreazza se firma como voz dissonante do mercado de livros". Jornal O Globo, Rio de Janeiro, 31/03/2016. Último acesso em http://oglobo.globo.com/cultura/ livros/editor-de-nomes-conservadores-carlosandreazza-se-firma-como-voz-dissonante-do-mercado-de-livros17021179\#ixzz4bFGqF5tQ no dia 13/03/2017. 
e saberes específicos, e são essenciais na repercussão que tal grupo de autores passam a ter com o público leitor brasileiro.

A forma de atuação da editora fica clara ao privilegiar a publicação de livros políticos de rápida circulação e absorção - mais conhecidos como instant books. Foram os casos dos já citados livros de Diogo Mainardi e Reinaldo Azevedo, que tinham o governo Lula como alvo privilegiado de suas críticas, na esteira do escândalo do mensalão. Durante o governo Dilma, já sob atuação de Carlos Andreazza como editor, foram publicados livros como Década Perdida: dez anos de PT no poder (2013), do historiador e apresentador da Rádio Jovem Pan ${ }^{12}$ Marco Antonio Villa, Não é a mamãe: para entender a era Dilma (2015) e Que horas ela vai: o diário da tragédia de Dilma (2016), ambos de Guilherme Fiuza, e Dilmês: O idioma da mulher sapiens (2015), de Celso Arnaldo Araujo. Outros nomes de destaque atualmente associados à nova direita foram impulsionados pelas publicações da Record: Rodrigo Constantino, presidente do Instituto Liberal, publicou o Esquerda Caviar: $A$ Hipocrisia dos Artistas e Intelectuais no Brasil e no Mundo (2013), com mais 50 mil exemplares vendidos, e outros autores jovens passaram a figurar no catálogo da editora como Flavio Morgenstein, autor de Por trás da máscara: do passe livre aos black blocs (2015), e Bruno Garschagen, com Pare de acreditar no Governo: por que os brasileiros não confiam nos políticos e amam o Estado (2015).

Além da Record, outras editoras começaram a moldar seus catálogos no sentido de publicar livros para este crescente público de direita. A editora Leya é exemplar neste sentido e tem uma atuação parecida com a que vem sendo estabelecida na Record. A Leya é um conglomerado editorial português formado em 2008 e que conta desde 2009 com uma filial no Brasil, além de suas filiais em Moçambique e Angola. Publicou com bastante sucesso comercial a série de "guias politicamente incorretos", dentre os quais o Guia Politicamente Incorreto da História do Brasil (2011), Guia politicamente incorreto da América Latina (2011), Guia politicamente incorreto da história do mundo (2013) e Guia Politicamente Incorreto da Economia Brasileira (2015), todos de autoria de Leandro Narloch, além do Guia politicamente incorreto da filosofia (2012), de Luiz Felipe Pondé. O tom de revisionismo histórico, em que se coloca em xeque teses até então consolidadas pela historiografia, unido a um sarcasmo iconoclasta, fazem parte da linguagem que obteve grande aderência do público $^{13}$. Ainda neste sentido é possível apontar outras publicações da editoria como o Ditadura à brasileira (2014), de Marco Antonio Villa.

À diferença das pequenas e médias editoras, os grandes grupos editoriais costumam diversificar bastante seus catálogos. É isso que explica que uma editora como a Record publique grande parte das obras da filósofa, escritora e militante política de esquerda Marcia Tiburi. Livros da autora dentre eles Como conversar com um fascista: reflexões sobre o cotidiano autoritário brasileiro (2015) e Feminismo em comum: para todas, todes e todos (2018) - foram publicados pela editora. Também a Leya tem uma atuação neste sentido, servindo como exemplo a publicação das obras do sociólogo Jessé Souza, que tem despontado como um dos grandes sucessos de venda de livros políticos para o público de esquerda, como

12 A própria Rádio Jovem Pan passou a ser identificada com a Nova Direita, atraindo para seus quadros comentaristas como Reinaldo Azevedo, Raquel Sherazade e Marco Antonio Villa. Sobre este processo, ver: DUALIBI, Julia. A nova sinfonia paulistana: como a rádio Jovem Pan se reinventou ao dar voz para o sentimento antipetista em São Paulo. Revista Piauí, edição 106, julho, 2015.

13 Embora não seja objetivo deste artigo estabelecer uma comparação, é possível apontar que um processo bastante similar vem ocorrendo na Argentina. A atuação editorial da filial portenha da Random House-Sudamericana, que teve na sua coordenação entre 2005 e 2012 o jornalista e editor Pablo Avelludo - hoje Ministro da Cultura do governo Maurício Macri -, aponta para a consolidação da lógica de publicação de livros políticos, muitos deles com as características dos instant books típicas dos grandes grupos e com pautas temáticas que vão desde o revisionismo histórico em relação ao período da ditadura militar até a crítica aos governos dos Kirchner (2003-2015) e à pauta dos direitos humanos por eles encampada (GIORDANO; SOLER, 2015; SAFERSTEIN, 2017). 
nos casos de A radiografia do golpe: entenda como e por que você foi enganado (2016) e $A$ elite do atraso (2017).

Outras editoras de menor porte têm se destacado na publicação de obras para o público da nova direita. É o caso da Edições de Janeiro, que publicou $O$ Mito do Governo Grátis: o mal das políticas econômicas ilusórias e as lições de 13 países para o Brasil mudar (2014), do economista Paulo Rabello de Castro; a Três Editorial, que publicou o manifesto Por que Virei à Direita (2012), de Luiz Felipe Pondé, Denis Rosenfield e João Pereira Coutinho; a Vide Editorial, que publicou uma nova edição de O Jardim das aflições (2015), de Olavo de Carvalho, e A corrupção da inteligência (2017), de Flavio Gordon, além do já citado caso da editora É Realizações.

A disseminação de editoras que passam a configurar seus catálogos tendo em vista o público interessado nos autores ligados intelectualmente ao campo político da direita, e o sucesso de vendas que estes livros alcançam, deixa claro que esta tendência se estabelece de forma consolidada no universo cultural do país e exerce significativa influência no debate público.

\section{Considerações finais}

É inegável a grande aceitação e repercussão dos livros associados à nova direita, tendo na figura de Carlos Andreazza, na editora Record, um dos eixos norteadores desse empreendimento no Brasil. A partir da observação de parte do catálogo da editora, tem-se a dimensão das formas de materialização e disseminação das ideias em um momento político tão polarizado como o atual. Se os debates tomam rumos imprevisíveis e se desdobram em arenas muitas vezes intangíveis, com atores os mais diversos tais quais o sistema político, judiciário e os meios de comunicação de massa -, a análise da atuação das editoras, tendo em vista suas estratégias, seus públicos e sua repercussão, pode ser um excelente indício de como grande parte das ideias circulam e alimentam as convicções, são organizadas e deixam seus rastros de forma mais perene, não somente ampliando discussões, mas deixando registros bastante representativos das mudanças pelas quais passa a sociedade brasileira.

\section{Referências}

BAERT, P. "Positioning Theory and Intellectual Interventions". Journal for the Theory of Social Behaviour, v. 42, n. 3, p. 304-324, 2012.

BOURDIEU, P. "Une révolution conservatrice dans l'édition". Actes de la recherché en science socieales, 1999.

CHALOUB, J.; BOM JARDIM, F. P. "Intelectuais da "nova direita" brasileira: ideias, retórica e prática política”. Insight Inteligência, v. 72, n. janmar, p. 25-41, 2016.

DARNTON, R. "La France, ton café fout le camp !" Actes de la recherche en sciences sociales, v. 100, n. 1, p. 16-26, 1993.

DARNTON, R. A Questão dos Livros. São Paulo: Companhia das Letras, 2010.

GIORDANO, V. “QQué hay de nuevo en las "nuevas derechas"?" Nueva Sociedad, v. noviembre-, p. 1-17, 2014.

GIORDANO, V.; SOLER, L. "Editoriales, thinktanks y política: La producción y circulación de las ideas de las nuevas derechas en Argentina”. Revista Paraguaya de Sociologia, v. 52, n. 147, p. 35-50, 2015.

\section{HALLEWELL, L. O Livro no Brasil: sua história.} São Paulo: EDUSP, 2005.

MEDEIROS, N. “O objecto dúctil: a emergência de uma sociologia histórica da edição". Tempo Social, revista de sociologia da USP, v. 22, n. 2, p. 241-261, 2010.

ROCHA, C. "Direitas em rede: think tanks de direita na América Latina". In: VELASCO e CRUZ; KAYSEL; CODAS (org.). Direita Volver: 
o retorno da direita e o ciclo político brasileiro. São Paulo: Editora Fundação Perseu Abramo, 2015.

ROCHA, C. "Passando o bastão: a nova geração de liberais brasileiros". Disponível em: <http:// journals.openedition.org/nuevomundo/71327>. Acesso em: 10 out. 2017.

SAFERSTEIN, E. "La edición como intervención cultural, comercial y política: best-sellers políticos del director de Random House-Sudamericana en el kirchnerismo". MILLCAYAC - Revista Digital de Ciencias Sociales, v. IV, n. 7, p. 141-164, 2017.

SCHFFRIN, A. O negócio dos livros: como as grandes corporações decidem o que você lê. Rio de Janeiro: Casa da Palavra, 2006.

SCHWARZ, R. “Cultura e Política, 1964-1969”. O Pai de Família e Outros Estudos, p. 61-92, 1975.

SILVA, L. N. DA. Projeto gráfico como projeto editorial: um estudo de caso da editora Cosac Naify. [s.l.] Universidade Federal do Rio de Janeiro, 2014.

SILVA, L. N. DA. "Polarização política no mercado editorial brasileiro". Escuta: revista de política e cultural, 2018a.

SILVA, L. N. DA. "As primeiras coleções de ciências sociais no Brasil: Elementos para a análise da emergência de um gênero". Revista Enfoques, v. 16, p. 60-67, 2018b.

SINGER, A. Os sentidos do Lulismo: reforma gradual e pacto conservador. São Paulo: Companhia das Letras, 2012.

SORÁ, G. "Editores y Editoriales de Ciencias Sociales: un capital específico". In: Intelectuales y Expertos: La cosnstitución del conocimiento social en la Argentina. Buenos Aires: Paidós, 2004. the transformation of academic and higher education publishing in Britain and the United States. Cambridge: Polity Press, 2005. 